\title{
Insights on Professional Identification and Licensure from Community Practice Social
}

\section{Workers}

\author{
Elizabeth Lightfoot ${ }^{\mathrm{a}}$, Mary Nienow ${ }^{\mathrm{b}}$, Kao Nou L. Moua ${ }^{\mathrm{c}}$, Gregg Colburn ${ }^{\mathrm{d}} \&$ Alissa Petri ${ }^{\mathrm{e}}$ \\ a, b, c, d, e, School of Social Work, University of Minnesota, St. Paul, MN, USA
}

This is an Accepted Manuscript of an article published by Routledge in Journal of Community Practice in May, 2016, available online: https://doi.org/10.1080/10705422.2016.1165328

It is deposited under the terms of the Creative Commons Attribution-NonCommercialNoDerivatives License (http://creativecommons.org/licenses/by-nc-nd/4.0/), which permits noncommercial re-use, distribution, and reproduction in any medium, provided the original work is properly cited, and is not altered, transformed, or built upon in any way. 


\begin{abstract}
This article describes a qualitative study designed to explore both how community practice social workers identify professionally and to examine their view towards professional regulation. Thirty-five MSW-level social workers in a large metropolitan region who selfidentified as community practice social worker participated in in-depth interviews. The respondents shared their views regarding professional identification as social workers and the impact of professional identity on their work as community practitioners. Approximately half of the respondents indicated that they only sometimes or never identify as a social worker. The respondents were generally critical of the licensing burden placed upon them as community practice social workers.
\end{abstract}

\title{
Introduction
}

Community practice social work holds an important place in the history of the social work profession. Community organizing, administration, advocacy, and policy practice have always been integral parts of the social work field. Despite the historical importance of community practice social work, the profession has devoted increased attention and resources to direct or clinical practice social work in recent decades. Both direct practice and clinical practice, which are sometimes grouped together into the category micro practice, are primarily concerned with providing services or interventions directly with individuals or families. For purposes of this article, we use the terms direct practice or clinical practice to refer to scopes of practice that involve service to individuals or families, and community practice or macro practice for scopes of practice that involves systemic or community-level activities. 
Along with the increased attention and resources to direct and clinical practice, there has been a parallel increase in professionalization and professional regulation. The professionalization of the field has prompted talk of a crisis in community or macro practice social work for several decades (McNutt, 1995), and recent calls to "recalibrate the balance between micro and macro social work" (Rothman \& Mizrahi, 2014, p. 91). However, the field's move away from community practice social work has caused many community practitioners to operate in isolation or without a strong connection to the field of social work (Hill, Ferguson \& Erickson, 2010). There has been little exploration of the effects of this increasing shift toward clinical practice and professional regulation on how community practice social workers identify with the field. This study seeks to fill this void in the research by identifying important themes regarding professional identification and licensure among graduate-level community practice social workers.

\section{Background}

Unlike other professional fields, such as nursing or medicine, there has been relatively little research into professional identity development or professional ties to the field of social work among practitioners (Whitaker, 2008), despite the emphasis in social work education on professional socialization (Barretti, 2004; Miller, 2013; Weiss, Gal, \& Cnaan, 2004) and the ongoing debates in the field on defining the profession (Gibelman, 1999). The research that does exist tends to be localized and nongeneralizable beyond the specific groups under study. For example, Koeske, Lichtenwalter, and Koeske (2005) found that 214 Pittsburgh social workers with a BSW or MSW only slightly agreed with statements indicating professional social work identification. Another study by Bayne-Smith, Mizrahi, Korazim-Körösy, and Garcia (2014) 
looked at how professional identity changed overtime in relation to one's interprofessional collaboration activities. Additional research has tended to focus on the role of career interests, attitudes, and values, usually among students, but not on the processes of socialization within the field (Barretti, 2004; Bogo, Raphael, \& Roberts, 1993; Carpenter \& Platt, 1997; Miller, 2013; Mizrahi \& Dodd, 2013; Schreiber, 1989; Segal-Engelchin \& Kaufman, 2008). This lack of research on professional identity among social work practitioners is surprising, considering the shadow that Abraham Flexner's 1915 pronouncement on social work not being a true profession (Flexner, 1915) has had on the field of social work (Austin, 1983) and the various concerns about the development and identification of social work as a credible profession since that time (Condie, Hanson, Lang, Moss, \& Kane, 1978; Gibelman, 1999; LeCroy \& Stinson, 2004).

There is some research exploring the tendency of community practice social workers to fail to identify with the field of social work in contrast to the clear identification of direct practice social workers. A variety of reasons have been proposed to explain the reluctance of community practice social workers to identify as social workers, including the growing prominence in the field on direct or clinical practice (Ezell, Chernesky, \& Healy, 2004; Hill, Ferguson, \& Erickson, 2010; Rothman \& Mizrahi, 2014); the strong emphasis in social work education on direct practice (Ezell et al., 2004; Fisher \& Corciullo, 2011; Mizrahi, 2001; Rothman \& Mizrahi, 2014); the lack of quality field placements for community practice students (Hill et al., 2010; Holtz Deal, Hopkins, Fisher, \& Hartin, 2007); the prevailing conservative political climate through the last half of the 20th century and early 21 st century (Fisher \& Corciullo, 2011; Schneider \& Netting, 1999); and the preponderance of professionals from other fields, such as public affairs or urban development, involved in community practice roles, such as working as a community organizer, policy analyst, or political advocate (Starr, Mizrahi, \& 
Gurzinsky, 1999). In addition, the increased emphasis on professional regulation in the form of licensure could affect professional identification.

The one study of professional identity among graduate-level community practice social workers was an alumni survey conducted 15 years ago at Hunter College's School of Social Work (Starr et al., 1999). This study found that $91 \%$ of respondents who had majored in community practice identified as social workers, although the majority of those surveyed had social work jobs that were not community practice oriented. This study also found that many of those who were involved in community practice identified as both social workers and organizers or advocates. There are no other published research articles that directly address the issue of community practice professional identification, or the views of community practice social workers regarding licensure.

\section{Methods}

The purpose of this study is to explore how graduate-level community practice social workers working in the field professionally identify with the field of social work, and to explore how these social workers view licensure in regards to community practice social work. Specifically, we sought to answer the following research questions: a) How do community practice social workers professionally identify in relation to the field of social work? b) What are community practice social workers' views toward professional licensing?

\section{Sample}

The inclusion criteria for this study were broad: Respondents had to be a selfidentified community practice social worker who had received an MSW degree. The respondents 
consisted of a convenience sample of $35 \mathrm{MSW}$-level community practice social workers from a large metropolitan region. Respondents had a range of post-MSW work experience from 1 to 38 years, with a mean of 11.26 years of post-MSW practice experience. They graduated from eight different MSW programs. Respondents held a variety of positions, including community organizer, executive director, program coordinator, outreach specialist, consultant, and educator. The majority of respondents reported that they worked for non-profit organizations.

In the state where the interviews were conducted, there were four levels of licensure at the time of the study. All levels require a social work degree from a school that is accredited by the Council on Social Work Education. The first level, Licensed Social Worker (LSW), is for those with a Bachelor of Social Work who have passed the Association of Social Work Board (ASWB) Bachelors Exam. As of June 30, 2012, there were nearly 6,000 LSWs. The next three levels require a Master of Social Work (MSW) or a Doctorate of Social Work. These levels are: Licensed Graduate Social Worker (LGSW) which requires the ASWB Masters exam, with just over 1,500 licensees; Licensed Independent Social Worker (LISW) which requires the ASWB Advanced Generalist exam and has less than 800 licensees; and Licensed Clinical Independent Social Worker (LICSW) which requires the ASWB clinical exam and has nearly 4,500 licensees. Varying levels of supervision and direct client contact hours are required at each of these levels. In the sample, 20 respondents were licensed social workers, and 15 did not hold a social work license. Of those with licenses, 1 respondent held an LSW, 7 held an LGSW, 10 held an LISW, 1 held an LICSW and 1 held a license from a neighboring state.

\section{Recruitment}


The study participants were recruited via one post on a social work Facebook page in the state with many followers, one post on the state's macro practice Facebook page, and one e-mail sent to a listserv of community practice social workers, maintained by a local macro social work networking group. This method was chosen over using a list of those who were members of a professional social work organization to ensure that we were reaching community practitioners who did regularly connect with the professional social work community, or using an alumni list of community practice programs, as we were interested in those practicing as community practitioners, rather than those who were educated as community practitioners. There were 35 respondents based on just these three posts. Potential respondents were asked to contact the research team via a dedicated e-mail address if they were interested in participating in an interview regarding their experiences as a community practice social worker. All those who contacted the research team met the inclusion criteria and had an interviewed scheduled. Respondents were not compensated for their participation.

\section{Data collection}

Semistructured interviews were used to collect data from the 35 respondents. The interview guide asked questions regarding professional identification, including probes about how respondents identified with the field of social work, rationales for identifying or not identifying professionally as a social worker, and the benefits and detriments of identifying professionally. In addition, the interview guide asked questions regarding their views of licensing for community practice social workers. The interview used a semistructured format so that interviewers could probe for additional details and respondents could elaborate on their answers. 
Twelve MSW students enrolled in a community practice social work course served as interviewers in this study. All students who chose to participate were trained in research methods, conducted practice research interviews, and completed human subjects training. The study coordinator matched potential respondents and members of the research team to schedule in-person interviews. In-person interviews were scheduled at a location of convenience for the respondents, most commonly in the respondent's office. Prior to the interview, an informed consent form describing the purpose of the study and the confidentiality of the data was provided for the respondent to review and sign. Interviews lasted approximately 1 hour. All interviews were digitally recorded and transcribed verbatim by the interviewers, and to ensure completeness of the data, all transcripts were reviewed for accuracy by the first author.

\section{Data analysis}

The transcripts from the interviews were analyzed by a research team including the principal investigator, who is a community practice social work educator; three $\mathrm{PhD}$ students with community practice orientations; and one MSW student. Using a thematic content analysis approach (Miles \& Huberman, 1994), the principal investigator and the four other members of the research team first coded the data separately to reduce the data into core, emerging themes. Data were coded into conceptual codes and subcodes, and also participant perspective and characteristic coding was used (Bradley, Currey, \& Devers, 2007). Themes were determined collaboratively by all authors through extensive data display and discussion over multiple sessions. Transcripts then were recoded by the principal investigator using the set of themes to test for consistency of themes and enhance rigor (Miles \& Huberman, 1994). Final themes and 
relationships among themes were agreed upon collectively by team members. The themes are presented below in order of magnitude.

\section{Limitations}

One of the limitations of this study was the use of multiple interviewers for the project. Although it is not uncommon for qualitative studies to use multiple interviewers, particularly in funded projects employing qualitative research teams, using multiple interviewers can reduce the consistency of findings in that different interviewers can elicit different levels of detail or focus more strongly on different parts of an interview (Pezalla, Pettigrew, \& Miller-Day, 2012). This study attempted to mitigate this limitation by ensuring consistency of the research procedures, as suggested by Pezalla et al. (2012), through training team members about research methods and ethical considerations, and conducting practice interviews.

A second limitation was that this study used a purposive sampling method with a preset number of respondents, rather than a theoretical sampling strategy. Ideally, the interviews would have continued until theoretical saturation had been reached. However, due to budgetary and time constraints, the interviews were scheduled prior to the completion of the data analysis. Further, using social media and a community practice listserv as recruitment strategy would not reach those community social workers who are not connected to these types of sites. Finally, as with all studies using non-probability sampling strategies, the findings cannot be generalized beyond this sample of community practice social workers and should be interpreted with this limitation in mind.

\section{Findings}


The findings section first reports on how the respondents professionally identified as social workers, and the benefits and detriments with such identification. Next, it presents the respondents' views on licensing of community practice social workers.

\section{Professional identification as a social worker}

The respondents in this study were mixed in how they identified professionally as a social worker. Respondents were asked if they identified as a social worker, and to describe their identification. The authors classified the open-ended responses into three categories: sometimes, rarely or never, or usually or always. Fifty-one percent (18) of the respondents sometimes, rarely, or never identified professionally as a social worker; $48 \%$ (17) usually or always usually identified professionally as a social worker. Eighty-eight percent (15) of those who always or usually identify as a social worker were currently licensed. There was no correspondence in professionally identifying as a social worker and the type of license, years of practice, or from which MSW program that respondents graduated.

A few of those who discussed identifying as a social worker were enthusiastic about this identification. For example, a licensed respondent said, "Yeah, I claim social work. I wear a flag. Yes. Social work is more than ... it's a calling for many, many people. It's a calling for me. So there's pride in that degree and in that career, in that profession." Others who indicated professionally identifying as a social worker expressed frustration about others not being familiar with social work. A licensed respondent said, “And so I think every time I identify myself as a social worker to people, and I, inevitably I have the conversation where I have to say this is social work too." 
Thirty-four percent (12) of the respondents indicated that they only sometimes professionally identify as a social worker. Of those who sometimes professional identify, $33 \%$ (4) were licensed and 66\% (8) were currently unlicensed. Nearly all who described only sometimes professionally identifying only identified when it was useful for others to know that they were a social worker. For example, an unlicensed respondent described her professional identity as follows: "I use it when I need it. And if I don't need to use it, I don't." Likewise, a licensed respondent said,

Well, it depends on the audience. So I am selective about when I talk about it, and I think in community based work it's usually a plus. ... But with some audiences, it's not a plus. ... So I sort of decide when to talk about it and when not to talk about it.

Several identified as a social worker depending on the particular job title they held, so their professional social work identification changed during their career. As one licensed respondent said,

I don't identify myself as a social work just because my position doesn't require me to be a social worker. But if I were in the other jobs in which they require a person to be a social worker, I would identify myself as one.

Seventeen percent (6) of the respondents rarely or never identified professionally as a social worker, even though they classified their work as community practice social work. All of these respondents were currently unlicensed. All of these respondents described the social work professional identity as not being particularly helpful in their current position or careers. As described by a currently unlicensed respondent, "In this position that I work in, nobody really knows what an LICSW or an MSW is. So those initials have been dropped from my title." 


\section{Benefits and detriments of professionally identifying}

There were a number of themes related to benefits of professionally identifying as a social worker that emerged, however, overall there was much more emphasis among respondents on the detriments of professionally identifying, even by many of those who always identified as a social worker. First, the benefit-related themes are presented.

\section{Benefits of professionally identifying}

The major themes related to the benefits of professionally identifying as a social worker that emerged were: (a) connect with other social workers, (b) provide legitimacy as a professional, and (c) promote a broader view of social work that includes community practice. Those who professionally identified as social workers and/or were licensed social workers were more likely to discuss benefits of such identification, but those who did not professionally identify and those who were not licensed also cited a number of benefits. The themes are extrapolated in the following.

\section{Connect with other social workers}

The most common positive theme that emerged relating to professional identification was that it allowed for connections with other social workers. This theme was most often described by respondents who only sometimes identified professionally. A few respondents indicated that they might not ever identify as a social worker with other professionals or community members, but when communicating with social workers it brought a sense of credibility, mutual understanding, collegiality and camaraderie. For example, a licensed respondent said, 
When they see those letters behind my name ... it is an opportunity to kind of connect on something. They kind of have an understanding, Oh, ok, we may share a common theme here and we can talk about that. It is a way for me to make some rapport. That is one strategic reason for me doing that.

Several others talked about identifying as a social worker as a means to motivate social workers to take action or reflect upon social justice. For example, one unlicensed respondent stated, "For me, the best place to identify as a social worker is with social workers, so that I can challenge them and kind of say the stuff that they don't want to hear."

\section{Provide legitimacy as a professional}

Another benefit-related theme identified by about one-third of the respondents who strongly identified as social workers was that such identification gave the social worker legitimacy as a professional, both externally and internally. Emphasis was placed on how professionally identifying increased their validity as a professional in others' eyes. For example, one licensed respondent said, "They know that you've had education to do the work and that there's a set of ethical standards". This sense of legitimacy was helpful for internal legitimacy as well. One licensed respondent said, "The more you identify, the more you remind yourself, 'Oh yeah. I'm ... I'm a social worker."”

Promote a broader view of social work that includes community practice

Another theme that emerged from the interviews was that professionally identifying helped promote a broader view of social work that included community practice. This theme was noted particularly by those who were licensed and always or usually identified as a social 
worker. They discussed that because social work is often narrowly constructed by the public or even the field itself, respondents felt compelled to identify with the profession as a way of promoting community practice social work as core to the field. Several spoke about professional identification in advocacy or public education terms. As one licensed respondent said,

I do think it's really important to identify professionally as a social worker so people get a more comprehensive view of what social work is. Because it's really important, and it's core to what we say social work is. I mean, it's part of the curriculum, it's part of the expectations, and that social work is about the ecological model of making change all across the spectrum. So if we think that's true, macro practice social workers really need to be out there saying that we're social workers. And we need to educate the public more about it.

Similarly, another licensed respondent said,

I want to, um ... bring the focus of social work ... back to its origins. And so if the only people that are identifying as social workers are clinicians and case managers, that's what people are going to think of when they think of social workers. But if I identify as, I'm a macro-social worker, then people are like, “Oh! Is that a thing?" And I'm like, "Yes! Let me tell you why it is a thing."

This was sometimes described as a frustrating, but necessary activity, because they had to frequently explain themselves. As a licensed respondent noted, 
Every time I identify myself as a social worker to people ... I have the conversation where I have to say this is social work too. Even though it annoys me, it helps give a bigger picture of what social work is.

Detriments associated with community practitioners identifying as a social worker

Nearly all respondents noted the difficulties associated with community practitioners professionally identifying as social workers. An overarching theme that emerged from the interviews was a lack of pride in the field and the direction the field of social work is heading. This theme was evident in over half of the interviews, and in almost all of the respondents who only sometimes, rarely or never identified as a social worker. This lack of pride theme was only lacking amongst those who strongly identified with the field and were firmly supportive of social work licensing. The lack of pride was usually framed in the context of social work becoming too narrowly constructed or too focused on professionalism, not in a lack of pride in their own work or the work of other social workers. Rather, this theme related to the overall direction of the field. This unlicensed respondent's comment typifies this theme:

I don't agree with a lot of the ways in which it is now playing out to be a professional or to be competent, or whatever the new hot buzz word is going to be.... I'm not in a place right now that I share that or that I take very much pride in that.

Although lack of pride was an overarching theme related to the detriments of professional identification, four subthemes emerged including; (a) the community doesn't understand what social work is, (b) negative connotations of social work, (c) social work as part of the problem, and d) respondents can't identify because of licensing regulations. These additional subthemes are described in more detail in the following. 


\section{The community doesn't understand what social work is}

A common theme that arose in more than half of the interviews was that many professionals and community members do not understand the field of social work or the scope of its work. As one licensed respondent said, "I don't think that term [social work] has meaning outside the profession. I think social workers want to think it does, but it doesn't." Some respondents indicated that they only identified as a social worker if they knew the person or group they were addressing had an understanding of the different aspects of the profession (direct and community practice). Others said that although identifying as a social worker is useful when interacting with other social workers, many community practice social workers are in settings with few or no other social workers, and identifying professionally in these settings can cause confusion.

Respondents also indicated that community members, professionals, and even other social workers perceived social work as limited to only direct practice. As one licensed respondent said, "Well, it's funny because you tell people you're a social worker and they assume that you are a therapist." Another licensed respondent said, "People have an image of a clinical social worker, of a therapist. And so you kinda get pegged, so there are assumptions that go with what it means to be a social worker." Several discussed how this view of social work as direct micro practice required them to repeatedly explain to others about the broad nature of the field. A few respondents found this to be a good segue to promote community practice social work. As one unlicensed respondent said, "I see an opportunity for engagement and for education." Others talked about how this more narrow view resulted in not identifying 
professionally as a social worker because it was too difficult, too confusing, and not worth the effort. As one unlicensed worker said,

I don't think in the future I will recognize myself as a social worker because I don't know if [my practice area] will understand what a social worker would be doing in the position. ... I would have to explain it to them every time.

Another unlicensed respondent reported, "If I said social worker, they would think I did something else completely."

Negative connotations of social work

A related theme that arose in nearly a quarter of the interviews was the negative connotations of social work by many in the community. By identifying as a social worker, these negative connotations can hinder community practitioners' ability to build important relationships. This theme came up repeatedly in the interviews, and was discussed regardless of professional identification or licensing status. Respondents concerned about this negative reaction often used their position title or more generic terms, such as community organizer or policy advocate, rather than social worker when describing their professional role.

There were a variety of general negative connotations mentioned, but most fell into three specific subthemes: (a) social workers as "leftists," (b) social workers as unsophisticated, and (c) social workers as "baby snatchers." Respondents discussed the frequent stereotype they heard of social workers as having a leftist political bent, which made identifying as a social worker difficult for those doing community organizing or legislative advocacy. One licensed respondent described the difficulties of this perception for those involved in lobbying. "In political 
advocacy, that can come off as a challenge, especially in working with more conservative people."

A second specific negative connotation was that social workers were not particularly smart or savvy. This negative stereotype of social workers seemed a deterrent to professional identification. One licensed respondent, though indicating that she does identify regularly as a social worker, describes this internal tension of identifying in the face of negative connotations of social workers as follows:

You know, you say I'm a social worker ... and then I would say outside of certain fields, social workers are not, not perceived to be high caliber people. ... And that frustrates me, so sometimes when I say I'm a social workers, there's part of me that thinks, "Now they think I'm a dummy." Or, “Now they think that I can't be strategic, that I can't be um, tough as nails."

Finally, several respondents also discussed how the stereotype that social workers are "baby snatchers" is a hindrance for working in communities or with other professionals.

\section{$\underline{\text { Social workers as part of the problem }}$}

Another theme regarding identifying professionally discussed by five of the respondents was that certain communities or members of communities considered the profession of social work as perpetuating a bureaucracy that was not helpful to their clients. Social workers were perceived to be part of the problem. This theme was identified only by those who only sometimes, rarely, or never identify professionally as a social worker. By identifying as a social worker, respondents worried about distancing themselves from the communities they were trying 
to serve. This was particularly the case for respondents working within certain communities, such as those affected by domestic violence. One unlicensed respondent said,

By identifying as a social worker within an activist community you can be seen as part of the problem.... With community work sometimes you're seen as an enabler or someone who perpetuates bureaucracy. So I think I try to make it simple [by not identifying].

\section{Can't identify as social worker because of licensing}

Finally, a small theme that emerged in three of the interviews was that respondents did not publicly identify as a social worker because of licensing laws, and several others noted that their confusion about the laws limited their likelihood to identify. Rather than the laws compelling them to become licensed, the law deterred them from identifying as a social worker. As one respondent said, "There ends up being this whole thing where you don't want to identify as a social worker because the fact that you're not licensed, which is a challenge for macro social workers." However, this was complicated for the respondents, as respondents noted that the type of social work that community practitioners do is not always covered by the licensing laws. This created confusion, and resulted in respondents who wanted to identify as social workers being leery about identifying, because the licensing board said they were not practicing social work.

\section{Views toward licensing of community practice social workers}

The respondents in this study had mixed views about licensing of community practice social workers. Although positive themes emerged related to the benefits of licensing for community practice social workers, negative themes regarding licensing were more prevalent.

Overall, just over $10 \%$ (4) of the respondents, all licensed, were very positive towards licensing 
for community practice social workers, $23 \%$ (8) of the respondents were positive toward licensing but had some reservations, $40 \%$ (14) of respondents were negative toward licensing, but saw some potential benefits, and 25\% (9) of respondents were very negative toward licensing. There was no correspondence in views toward licensing by a respondent's type of license, years of practice, or MSW program.

\section{$\underline{\text { Positive aspects of licensing for community practice social workers }}$}

Four themes related to the benefits of licensing for community practitioners were revealed in the interviews, including: (a) opens doors to job opportunities, (b) provides professional credibility, (c) legitimizes the profession, and (d) provides supervision opportunities. It's important to note that public protection as a benefit of licensing was discussed by only 3 of the 35 respondents during the interviews.

\section{Opens door to job opportunities}

The most common benefit-related theme was that licensing was an avenue to increased job opportunities. Both unlicensed and licensed respondents described licensing as beneficial to employment. Licenses were often described as a credential, or as a licensed respondent said, "something else, more to add to my resume." Several respondents used the metaphors "opening doors" or "foot in the door." For example, an unlicensed respondent said, "I think it would get my foot in the door in more social work settings;" another licensed respondent said,

I think it does help in terms of job search and opening doors. People see your license and whether they require it or not it's another level of credential that tells people you're 
taking your work seriously and you have completed all the steps to do your licensure, which isn't an easy process.

\section{Gives professional credibility}

A similar positive theme discussed primarily by licensed respondents was the professional credibility associated with licensing. This credibility was described as useful for employment purposes, as well as for professional credibility more broadly. This was particularly noted by respondents who were in positions where they worked with many other licensed professionals. As one licensed respondent stated,

Keeping in mind that many people who come here come with an $\mathrm{LIC}$, a $\mathrm{PhD}$, and an LP or any other kind of licensure, so it's really important for the executive director of this organization to also have some kind of professional licensure.

The credibility of licensing was often described in terms of credentialing, sometimes in terms of having "initials" after their name. For example, one licensed respondent said, "So I don't know what the benefit really is, other than for having letters after your name and can bring up conversation and I guess give you a certain level of expertise that other people don't have, and credibility."

\section{$\underline{\text { Legitimizes the profession }}$}

Another theme described by the majority of the respondents who were also in favor of licensing was that licensing legitimizes and elevates the profession. Respondents talked about this generally, such as how the larger field of social work benefits from licensure. For example, a licensed respondent discussed how licensure "enhances the profession, it talks to the skill level 
and the knowledge level that we have developed." Another licensed respondent spoke about licensing as allowing "you to support the profession and make the profession a legit profession and so on ... [and show] the other people that you actually care about the profession." Others talked about how licensure for community practice social workers legitimizes the subfield of community practice. For example, a licensed respondent expressed, "For me it's important to hold the license because it's important that we recognize that community practice is a distinct area of work in that it is just as challenging and skill-laden as clinical practice."

\section{$\underline{\text { Provides supervision opportunities }}$}

The final benefit-related theme of licensure for community practitioners noted by respondents was the supervision requirements required by the state. Although respondents also discussed the difficulties in finding appropriate community practice supervisors and the associated costs, supervision was always mentioned as a desired aspect of professional development. This benefit was cited by both those who were and were not licensed, and by those with divergent views regarding licensing.

\section{Drawbacks of licensing for community practice social workers}

The major drawback-related themes that emerged with how licensure is currently constructed were, (a) licensure as currently constructed is not relevant to community practice, (b) the licensing process is burdensome, (c) licensing benefits are not worth the costs, (d) licensing takes community practitioners away from the communities, and (e) licensure is only in place to perpetuate the existence of the social work licensing board. These negative themes represented more of the total discussion among respondents than the positive aspects described previously. 


\section{Licensing not relevant to community practice}

A central theme related to the drawbacks of licensure found in the interviews was that licensure simply was irrelevant to community practice social work. This theme included a number of sub-themes, including: (a) a social work license is not needed for community practice jobs, (b) licensure does not bring credibility to community practice social workers, and (c) social work licensing is too clinical. These sub-themes are discussed below.

\section{$\underline{\text { License not needed for community practice jobs }}$}

The subtheme, license not needed for community practice jobs, was discussed by nearly three fourths (26) of the respondents. These respondents indicated that few community practice positions require a license, and many organizations did not care if a community practice social worker had a license. An unlicensed respondent discussed licensing in the following way:

I don't have one because I don't feel that I need one, because my job doesn't require one. I actually took the test because I thought I would ... why not? And then I thought it would be helpful, but now there is no one in my agency in my division who could do my supervision so I couldn't do supervision without paying for it. It's not worth it to me to pay for supervision because I don't need it.

Some respondents who had licenses described how their organizations did not recognize their license. For example, one licensed respondent said,

Here at [my organization] no one cares that I'm licensed. They probably don't even care that I'm a social worker. I mean, you know, when I apply for jobs, I have my shtick about 
why it matters that I'm a social worker, and so, it may matter to them. But, it's not like they're highlighting, "Oh, we have a licensed social worker on staff."

Several respondents discussed their ambivalence about not having their license, even if it was not necessary. One unlicensed respondent said,

I certainly didn't need it in my last job, I don't need it now. ... Part of me still wants to. I have no idea how I would pass. Being out of school ... and like, the test is so clinical I don't know how the heck I would pass it. ... Part of me feels like ... It's sort of your professional responsibility to have a license. But for community practice, it is totally unnecessary.

\section{No real credibility}

In contrast to the positive subtheme related to credibility previously noted, a negative subtheme emerged more frequently. While acknowledging that licensing gave credibility to some social work practice areas, approximately half of respondents (18) noted that licensure does not provide credibility for community practitioners. For example, a licensed respondent said,

It is a joke to think that being a licensed social worker somehow gives you credibility with the macro practice world. Now, if ... I wanted to be the executive director of a mental health agency it would help me. So, don't get me wrong. But do you think that any legislator cares whether I'm a social worker? They don't care.

Similarly, an unlicensed worker said that licensure "doesn't seem to carry a whole lot of weight in the space that I work." 


\section{Licensing too clinical}

Another negative subtheme that was common in interviews of both licensed and unlicensed respondents was that licensing was too clinically oriented and not relevant to community practice social work. This subtheme was present among all those who were generally positive toward licensing, but skeptical toward the current licensing structure and process. One licensed respondent said,

I'm licensed at the independent clinical [level], but it doesn't acknowledge my community practice work whatsoever. ... I think because we don't recognize as a profession, we don't see community practice as equally important as direct, the clinical and clinical practice.

Likewise, another unlicensed worker said,

I feel that licensure is really important. It's just not for me. Which is sad! But if they had ... I mean I don't think the licensure system is set up for community practice folks. One, there is no benefit. And two, the license is all clinical, so what would be the point?

This quote was typical among those who felt ambivalent toward licensing. Respondents had respect for licensing for clinical social workers, but viewed that licensure was not applicable to the work of community practitioners.

These respondents also discussed how the licensing exam is unrelated to their community practice work. This was repeatedly mentioned as a deterrent to taking the exam and becoming licensed, as well as an annoyance for those who were currently licensed. Although there was some concern about the potential for not passing the test, most expressed deeper concern for the 
mismatch between the exam and community practice skills. For example, one licensed worker explained why she chose not to go for a higher level of licensure in this way: "I believe the LISW exam is far too clinical for ... I think it misrepresents what I've been trained in. So, if I did pass that test and carried an LISW licensure, I believe that it misrepresents my knowledge base."

\section{Process of licensing is a burden to community practice social workers}

A strong theme present in almost three fourths of respondent interviews was that the licensing process was a burden for community practice social workers. Much of the tone of the discussion was vitriolic, with a great antipathy for the process. Many described licensing as a bureaucratic exercise of complying with a number of requirements that were unrelated to their work. A licensed respondent said, "I'll be honest; it seemed like hoops I had to jump through."

Nearly all the respondents noted that licensure was too expensive. They spoke of the financial burden of licensing for many community practitioners, as most organizations hiring community practice social workers will not pay for licensing expenses, continuing education classes or supervision. Several unlicensed respondents spoke about previously having their license, but giving up it up because of its expense and irrelevance.

Although most respondents were generally positive about the concept of supervision, many described the difficulties and additional expense associated with supervision. Because most community practitioners do not have a licensed supervisor within their organization, they have to find and pay for external supervision. A number of respondents discussed how the licensing board-approved continuing education offerings were irrelevant for their professional development. 


\section{$\underline{\text { Benefits are not worth the costs }}$}

Another prevalent theme in the interviews was that the benefits of licensing for community practitioners were not worth the costs. Many spoke of it directly as a cost-benefit calculation, though they were never directly asked to make such a calculation. This theme was brought up by both licensed and unlicensed respondents. For licensed respondents, there was frustration about the licensing requirements. One licensed respondent said, "The way it's set up right now is detrimental. It has nothing but cost. It has no benefit." Similarly, another licensed respondent said,

I mean, I'm self-employed so I pay for all my own CEUs, I pay for my license every other year ... which is $\$ 300$. They [the board of social work] give me nothing. They give me no benefit at all. It just infuriates me, as you can tell.

For most unlicensed respondents, the cost-benefit calculation was discussed as a rationale for not getting licensed. For example, an unlicensed respondent spoke of her own cost-benefit calculation like this:

I was able to find work I wanted to do without it, and so maintaining it to do all the things that you need to do, the fees, the supervision and all of that just didn't seem like it would benefit me in the end, to go through that when I'm doing the work that I've wanted to do without it.

Another unlicensed respondent spoke of the cost-benefit calculation this way,

I mean, it gives standardization to practice, it gives credibility, accountability, all of those things that I believe in, but because of its lack of recognition in the community, it does 
not offer me enough benefits to make the sacrifices to get the licensure.... What I am trying to say is that the financial burden of getting licensed is not outweighed by the benefits of it, and that is my number one reason not to get it.

\section{$\underline{\text { Licensing takes community practitioners away from communities }}$}

A more practice-oriented theme was that the process of licensing distances community practice social workers from communities, especially when community practitioners are working as community organizers or partnering with marginalized populations. An unlicensed respondent spoke of licensure in this way:

I do not find it beneficial to have a licensure for community practice. I think it's just another way in which our field is moving toward professionalism, and again another way in which we're moving farther and farther from the communities that we are working with.

Licensing serves to perpetuate the licensing body

A final theme that emerged was antipathy toward the state licensing body. This was a theme especially salient among licensed respondents. Licensing was described by one licensed respondent in this way, "the board of social work keeps making it harder and harder, because they're just trying to legitimize their existence, frankly." These types of comments were frequent within the interviews. A common concern was that the state licensing body doesn't understand community practice social work, and that the definition of social work is narrow and confusing. This was described both by licensed respondents, who felt like they had to prove to the licensing 
body that what they were doing was social work, and unlicensed respondents, who had tried to be licensed and were told they weren't doing social work.

Finally, there was a concern among some respondents that the state board of social work was focusing too much on regulation without recognizing the broad nature of social work or the

difficulties inherent in licensing for community practitioners. The social work board was referred to by one respondent as a "bully;" another spoke of being threatened with prosecution, and several spoke of licensing as being "forced" upon workers.

\section{Licensing levels and a community practice license}

Although respondents were not asked to discuss potential solutions to the licensing issue, several respondents discussed two potential changes to better fit with community practice social work. One suggested change was to make the clinical license and advanced generalist license the same level. Currently, in the state where respondents practiced, the clinical license is perceived to be a higher level license as it has more requirements even though they are technically the same level, and this was concerning for some of the respondents. In addition, there were suggestions that the advanced generalist licensing exam should be more balanced between direct and community practice exam questions.

A second change was to have a community or macro practice license. As one licensed respondent said:

I'm a big proponent in there should be a licensure that's specific to the macro practice that anybody can take, so if you're a social worker and you're doing direct practice, and 
you moved into supervision, you should be able to take it and become more of a macro practice.

These ideas were brought up primarily by licensed respondents who were in favor of licensing in

general, and none of the respondents who had negative views towards licensing suggested either change.

\section{Discussion}

This study found that that approximately half of the community practice social workers in this study routinely professionally identify as a social worker when working in the field. The choice not to identify professionally was linked to the state of the field of social work, concern with being misunderstood and perceived professionalization. Although these findings differ from the earlier study of community practice social workers by Starr et al. (1999), it is likely that the lower levels of professional identification are because the social workers in this study are in community practice positions; the majority of respondents in the Starr et al. (1999) study were in more direct practice or clinically focused social work jobs, even though their training was in community practice. Even among the respondents who indicated that they did identify

professionally as a social worker, nearly all respondents described numerous challenges associated with this, such as the confusion among other professionals and community members when they describe their community practice positions as social work.

The findings also indicate that the respondents believed that social work has an image problem and they believed the public does not view or understand community practice social work to be a part of the profession. They felt that this image problem directly affected their 
ability to practice as community practice social workers, and described using alternative professional titles when communicating with the public to avoid explaining the connection between their work and the inaccurate or negative images others might have of social work. Respondents dealt with this image problem in two primary ways. Some used the opportunity to educate the public about the broader notions of social work that include community practice; others chose to identify with another field so as to avoid the confusion associated with the professional identity of being a social worker, including any negative connotations. This should be a significant concern for the field of social work in general, and particularly for those concerned with the role of community practice social work within the field.

The public image concern that emerged in this study is certainly not a new one for social work. The profession's public image has been debated and studied repeatedly since its inception (Gibelman, 1999), with some studies indicating the public's positive perception of social work (LeCroy \& Stinson, 2004) and some indicating a negative public perception (Condie et al., 1978). Most studies of public perception support the findings of this study in that they have found that the public had a vague or narrow understanding of the profession of social work (Dennison, Poole, \& Qaqish, 2007; Jones, Vela, Vang, \& Walden, 2006; Williams, Simon, \& Bell, 2015; Zugazaga, Surette, Mendez, \& Otto, 2006). The problems that community practice social workers face related to the perception of social work as a narrow field with some negative connotations likely requires a concerted effort to change the image of social work.

In 2004, NASW launched such an effort in the form of a public image campaign that began with a series of focus groups and interviews to better understand what the public thought of the profession overall (NASW, 2005). One of NASW's findings echoed those of previous studies; that the public does not understand how diverse the field of social work is, including 
community practice social work as a key component of the profession (NASW, 2004). The campaign comprised a series of print and multimedia ads showing social workers in a variety of roles; a new slogan, "Help Starts Here;" videos for schools of social work promoting the stories of social work; and a campaign web site with links to the videos, a campaign tool kit, requests for donations, product merchandise for sale, and links to a consumer web site that offers consumers information on a variety of topics and access to a list of licensed social workers (NASW Foundation, n.d.). Our findings indicate that this perceived image problem still directly affects how community practice social workers feel they are understood by the public and that this in turn impacts their identification within the field.

The role of professional regulation was a hot button issue for most of the respondents in the study, with over half of the respondents having negative views of licensing, and only about $10 \%$ indicating strongly positive views. Although the purpose of professional regulation is to protect the public, less than $10 \%$ of respondents discussed public protection as a positive aspect of licensure. Three-quarters of the respondents in the survey reported that licensing was not relevant to their work nor a requirement for their current positions. Many indicated confusion and fear regarding licensure, and a few indicated simply not identifying as a social worker because of the licensing regulations. Although licensing is not intended to give benefits to the licensee, many respondents viewed licensing using a cost/benefit ratio and felt the costs outweighed the benefits. Respondents indicated that the most tangible benefit for getting a social work license was improved employment prospects. Many respondents described logistical challenges to licensure for community practice workers, such as having to pay for supervision, which was a requirement for licensure in their state. Others indicated practice issues surrounding licensure that could hurt their ability to practice authentically, such as how licensure might set up 
a power dynamic that further distances community practice social workers from communities. There is a risk that the licensure requirements, which some argue increase social work's legitimacy as a profession, may have the unintended consequence of pushing community practitioners out of the field.

\section{Implications}

There have been numerous efforts to bolster community practice as an important part of the field of social work and to strengthen community practice social workers' ties to the broader field, including a renewed focus on macro practice curriculum (Mizrahi, 2001; Rothman \& Mizrahi, 2014), an increased focus on evidence-based community practice interventions (Ohmer, 2008; Ohmer \& Korr, 2006), the development of national networking and advocacy groups like the Association for Community Organization and Social Administration (ACOSA)

(Mizrahi, 2001) and the Network for Social Work Management (Rothman \& Mizrahi, 2014), and the development of local networking groups such as the Association for Macro Practice Social Work in Minnesota (Hill et al., 2010). However, there has been less attention on some of the broader or more structural concerns that might be discouraging social workers interested in community practice from entering or remaining in these roles (Hill et al., 2010; Land, 1987; Mizrahi, 2006; Specht \& Courtney, 1994; Whitaker, 2008).

To address this concern, social work leaders, educators, and practitioners need to consider new proposals to foster growth and acceptance of community practice. ACOSA's (2014) recent launch of The Special Commission to Advance Macro Practice in Social Work, aims to address many of the concerns, such as tackling the licensing concerns of macro practitioners and promoting macro practice issues in major social work publicity efforts. In 
addition, the Special Commission is also intending to focus on how schools of social work can better integrate community practice into all aspects of their BSW, MSW, and PhD programs. These proposals should be thoroughly evaluated to measure which efforts lead to better integration of community practitioners into the broader field of social work, including measuring how the proposals lead to more students choosing community practice as a concentration, how many BSW and MSW graduates choose and continue in community practice type positions, how community practice content is reflected in broader discussions in professional organizations, and how many researchers are engaged in community practice related research efforts.

Aside from these efforts, there is a need to directly address the issues that some community practice social workers have regarding regulation. The field might consider alternative proposals regarding licensure for community practice social workers, such as a macro practice license, which exists in several states (Donaldson, Hill, Ferguson, Fogel, \& Erickson, 2014); a revamping of the current licensing system to ensure equity among all types of license holders; or considering waiving licensing requirements or instituting alternative registry systems for those involved in community practice work that does not involve direct contact with clients. At the very least, finding ways to make the licensing process more accessible, more relevant, and more affordable could help make community practice social workers feel more connected to social work and to be more likely to claim a social work identity.

Although, clearly, schools of social work need to address the role of community practice within social work education, local and national organizations can help promote community social work within the field, and boards of social work and the Association of Social Work Boards should address the real issues that community practitioners face in regards to licensure, this study shows that there are several other areas of action needed, as well. Most notably, the 
public's narrow and sometimes inaccurate view of social work requires a coordinated public marketing campaign, which would help the field as a whole, but also community practice in particular.

\section{References}

ACOSA, Special Commission Special Commission to Advance Macro Practice in Social Work. (2014). Summary report June, 2013 - June, 2014: Accomplishments in Phase One and future strategic directions and outcomes. Retrieved from https://www.acosa.org/joomla/pdf/FINALSpecialCommissionPhaseOneReport.pdf

Austin, D. (1983). The Flexner myth and the history of social work. Social Service Review, 57, 357-377. doi:10.1086/644113

Barretti, M. (2004). What do we know about the professional socialization of our students? Journal of Social Work Education, 40(2), 255-283.

Bayne-Smith, M., Mizrahi, T., Korazim-Körösy, Y., \& Garcia, M. (2014). Participation in interprofessional community collaboration. Issues in Interdisciplinary Studies, 32, 103133.

Bogo, M., Raphael, D., \& Roberts, R. (1993). Interests, activities and self-identification among social work students: Toward a definition of social work identity. Journal of Social Work Education, 29, 279-292. 
Bradley, E., Currey, L., \& Devers, K. (2007). Qualitative data analysis for health services research: Developing taxonomy, themes and theory. Health Services Research, 42, 17581772. doi:10.1111/j.1475-6773.2006.00684.x

Carpenter, M. C., \& Platt, S. (1997). Professional identity for clinical social workers: Impact of changes in health care delivery systems. Clinical Social Work Journal, 25, 337-350. doi:10.1023/A:1025790613308

Condie, C., Hanson, J., Lang, N., Moss, D., \& Kane, R. (1978). How the public views social work. Social Work, 23, 47-53.

Dennison, S. T., Poole, J., \& Qaqish, B. (2007). Students' perceptions of social work: Implications for strengthening the image of social work among college students. Social Work, 52, 350-360. doi:10.1093/sw/52.4.350

Donaldson, L., Hill, K., Ferguson, S., Fogel, S., \& Erickson, C. (2014). Contemporary social work licensure: Implications for macro social work practice and education. Social Work, 59, 52-61. doi:10.1093/sw/swt045

Ezell, M., Chernesky, R. H., \& Healy, L. M. (2004). The learning climate for administration students. Administration in Social Work, 28, 57-76. doi:10.1300/J147v28n01

Fisher, R., \& Corciullo, D. (2011). Rebuilding community organizing education in social work. Journal of Community Practice, 19, 355-368. doi:10.1080/10705422.2011.625537 
Flexner, A. (1915). “Is social work a profession?". Proceedings of the National Conference of Charities and Correction, 42nd Annual Session, Baltimore, Maryland, May 12-19, 1915 (pp. 576-590). Chicago, IL: The Hildmann Printing Co.

Gibelman, M. (1999). The search for identity: Defining social work—Past, present, future. Social Work, 44, 298-310. doi:10.1093/sw/44.4.298

Hill, K., Ferguson, S., \& Erickson, C. (2010). Sustaining and strengthening a macro identity: The association of macro practice social work. Journal of Community Practice, 18, 513-527. doi:10.1080/10705422.2010.519684

Holtz Deal, K., Hopkins, K., Fisher, L., \& Hartin, J. (2007). Field practicum experiences of macro-oriented graduate students: Are we doing them justice? Administration in Social Work, 31(4), 41-58. doi:10.1300/J147v31n04_05

Jones, C. A., Vela, E., Vang, T., \& Walden, B. D. (2006). Perceptions of social work: Undergraduate students assess the profession. Journal of Baccalaureate Social Work, $12,1-12$.

Koeske, G. F., Lichtenwalter, S., \& Koeske, R. D. (2005). Social workers' current and desired involvement in various practice activities. Administration in Social Work, 29(2), 63-84. doi:10.1300/J147v29n02_05

Land, H. (1987). The effects of licensure on student motivation and career choice. Social Work, $32,75-77$. 
LeCroy, C., \& Stinson, E. (2004). The public's perception of social work: Is it what we think it is? Social Work, 49, 164-17. doi:10.1093/sw/49.2.164

McNutt, J. (1995). The macro practice curriculum in graduate social work education: Results of a national study. Administration in Social Work, 19(3), 59-74. doi:10.1300/J147v19n03_04

Miles, M. B., \& Huberman, A. M. (1994). Qualitative data analysis: An expanded sourcebook. Thousand Oaks, CA: Sage Publications.

Miller, S. E. (2013). Professional socialization: A bridge between the explicit and implicit curricula. Journal of Social Work Education, 49, 368-386.

Mizrahi, T. (2001). The status of community organizing in 2001: Community practice context, complexities, contradictions, and contributions. Research on Social Work Practice, 11, 176-189. doi:10.1177/104973150101100204

Mizrahi, T. (2006). Where have all the community organizers gone? A study of Hunter CO alumna from 1996-2006: Perspectives on the competencies and values in the curriculum looking back and career tracks moving forward. Retrieved from http://www.hunter.cuny.edu/socwork/programs/community_organization/COPD_Al umi_Study_1995-2006.pdf

Mizrahi, T., \& Dodd, S. (2013). MSW students' perspectives on social work goals and social work activism before and after completing graduate education. Journal of Social Work Education, 49(4), 580-600. 
National Association of Social Workers. (2004). What does the public currently think of social workers? Retrieved from http://www.naswfoundation.org/imageCampaign/campaign/default.asp\#public

National Association of Social Workers. (2005). Firm named to plan public image drive. NASW News, 49 (1). Retrieved from https://www.socialworkers.org/pubs/news/2004/01/image.asp?back=yes

National Association of Social Workers Foundation. (n.d.) Learn more about the campaign. Retrieved from http://www.naswfoundation.org/imageCampaign/campaign/involved.asp

Ohmer, M., \& Korr, W. (2006). The effectiveness of community practice interventions: A review of the literature. Research on Social Work Practice, 16, 132-145. doi:10.1177/1049731505282204

Ohmer, M. L. (2008). Assessing and developing the evidence base of macro practice interventions with a community and neighborhood focus. Paradigm of evidence-based macro practice. Journal of Evidence-Based Social Work, 5, 519-547. doi:10.1080/15433710802084284

Pezalla, A., Pettigrew, J., \& Miller-Day, M. (2012). Researching the researcher-as-instrument: An exercise in interviewer self-reflexivity. Qualitative Research, 12, 165-185. doi:10.1177/1468794111422107

Rothman, J., \& Mizrahi, T. (2014). Balancing micro and macro practice: A challenge for social work. Social Work, 59, 91-93. doi:10.1093/sw/swt067 
Schneider, R. L., \& Netting, F. E. (1999). Influencing social policy in a time of devolution: Upholding social work's great tradition. Social Work, 44, 349-357. doi:10.1093/sw/44.4.349

Schreiber, M. S. (1989). Student peer groups: A key aspect of professional socialization in graduate social work education. Jewish Social Work Forum, 25, 33-42.

Segal-Engelchin, D., \& Kaufman, R. (2008). Micro or macro orientation? Israeli students' career interests in an antisocial era. Journal of Social Work Education, 44(3), 139-157. doi:10.5175/JSWE.2008.200600147

Specht, H., \& Courtney, M. (1994). Unfaithful angels: How social work has abandoned its mission. New York, NY: The Free Press.

Starr, R., Mizrahi, T., \& Gurzinsky, E. (1999). Where have all the organizers gone? Journal of Community Practice, 6(3), 23-48. doi:10.1300/J125v06n03_02

Weiss, I., Gal, J., \& Cnaan, R. A. (2004). Social work education as professional socialization. Journal of Social Service Research, 31, 13-31. doi:10.1300/J079v31n01

Whitaker, T. (2008). Who wants to be a social worker? Career influences and timing. NASW Membership Workforce Study. Washington, DC: National Association of Social Workers.

Williams, J., Simon, C., \& Bell, A. (2015). Missing the mark: The image of the social work profession in an African-American community. Journal of Ethnic and Cultural Diversity in Social Work, 24, 56-70. doi:10.1080/15313204.2014.954739 
Zugazaga, C. B., Surette, R. B., Mendez, M., \& Otto, C. W. (2006). Social worker perceptions of the portrayal of the profession in the news and entertainment media: An exploratory study. Journal of Social Work Education, 42, 621-636.

doi:10.5175/JSWE.2006.200500502 